\title{
Comparison of swab types for collection and analysis of microorganisms
}

\author{
Natalie Wise ${ }^{1}$, Sarah Wagner ${ }^{1}$, Travis J Worst ${ }^{1}$, Jon Sprague ${ }^{1}$, and Crystal Oechsle ${ }^{1}$ \\ ${ }^{1}$ Bowling Green State University
}

October 6, 2021

\begin{abstract}
The human microbiome has begun to emerge as a potential forensic tool, with varied applications ranging from unique identification to investigative leads that link individuals and/or locations. The relative abundance of the combined DNA of the microbiome, compared to human nuclear DNA, may expand potential sources of biological evidence, especially in cases with transfer or low-copy number DNA samples. This work sought to determine the optimal swab type for the collection and analysis of the microbiome. A bacterium (Proteus mirabilis) was deposited by pipette onto four swab types (cotton, flocked, dental applicators, and dissolvable), and extraction and real-time PCR quantitation of the bacterial DNA were performed, which allowed for absolute microbial DNA recovery and comparison of yields across the four sampling substrates. Flocked swabs had the highest yield ( $\sim 1240 \mathrm{ng})$ compared to the cotton swabs $(\sim 184 \mathrm{ng})$, dental applicators $(\sim 533 \mathrm{ng})$, and dissolvable swabs $(\sim 430$ $\mathrm{ng})$. The collection efficiency was further evaluated for cotton and flocked swabs using dried microbial samples spotted onto non-porous surfaces (treated wood, glass, plastic, and tile). Flocked swabs performed consistently better across wood, glass, and tile, but showed decreased recovery from plastic. The cotton swabs failed in the recovery of P. mirabilis DNA across all surfaces. Knowing the appropriate sampling substrate will be useful as others continue to investigate the use of the microbiome as a forensics tool.
\end{abstract}

\section{Hosted file}

MB032021070355.pdf available at https ://authorea.com/users/439873/articles/540683-comparisonof-swab-types-for-collection-and-analysis-of-microorganisms 